JOURNAL CLUB

\title{
5 versus 14 days of prednisone for acute COPD exacerbations
}

In this multicentre, double-blind, randomised control trial, a shorter 5-day course of glucocorticoids was compared with a 14-day course to assess non-inferiority. Patients received an initial dose of IV methylprednisone, then 4 days of oral prednisone, followed by further prednisone or a placebo. They all received antibiotics and inhaled corticosteroids and bronchodilators.

No differences were seen in the primary endpoint of time to next exacerbation within the follow-up period of 6 months. Similarly, there were no differences in many of the secondary endpoints, including overall mortality, requirement for mechanical ventilation and new or worsening hypertension or hyperglycaemia. Importantly, no difference was seen in incidence of side effects of steroids despite a reduced cumulative dose of over $70 \%$ in the short-term group.

The benefit gained from steroid treatment in acute exacerbations peaks within 5 days. This study confirms that further steroids seem neither to do more harm nor more good in the following 180 days. It appears that a short course of oral prednisone is as good for treating exacerbations; however, more research is needed to show that it also has benefits in the long term. At the very least, shorter courses are cheaper and reduce the polypharmacy burden on these patients.

- Leuppi JD, Schuetz P, Bingisser R, et al. Short-term vs conventional glucocorticoid therapy in acute exacerbations of chronic obstructive pulmonary disease The REDUCE Randomized Clinical Trial. JAMA 2013;309:2223-31.

Laura J Quint

Correspondence to Dr Laura Quint, SHO; laura.j.quint@gmail.com

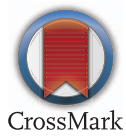

To cite Quint LJ. Thorax 2014;69:868.

Published Online First 10 September 2013

Thorax 2014;69:868. doi:10.1136/thoraxjnl-2013-204439 